\title{
Rare case of aplastic anemia precipitated by dapsone: A Case report
}

\author{
${ }^{1}$ Dr.Ravi Sehravat, ${ }^{2}$ Dr. Jyotirmay Singh, ${ }^{3}$ Dr.Poonam Malik, ${ }^{4}$ Dr. Manu Rathee \\ ${ }^{I}$ M.B.B.S, ,MD (Pharmacology) \\ ${ }^{2}$ B.D.S. ,M.D.S., Senior Lecturer, Department Of Orthodontics And Dentofacial Orthopedics, Dr. B.R. \\ Ambedkar Institute Of Dental Sciences \& Research, Patna. \\ ${ }^{3}$ B.D.S.,M.D.S., Senior lecturer, Department of Prosthodontics SGT Dental College and Research Institute \\ ,Gurgaon Haryana \\ ${ }^{4}$ MDS, DNB, MNAMS, FPFA, FICD Senior Professor And Head Of Department, Department Of Prosthodontics \\ And Crown \& Bridge Govt. Dental College Pt.B.D.Sharma Post Graduate Institute Of Medical Sciences \\ (PGIMS) Pt. B.D.Sharma University Of Health Sciences Rohtak, Haryana
}

\begin{abstract}
Dapsone is an antileprotic drug which is used most widely \& effectively in the long term treatment of leprosy. It inhibits folate synthesis \& is usually associated with GIT intolerance, rashes \& rarely with aplastic anemia. ${ }^{[1]}$ However, over the year's literature in form of case reports have accumulated which shows that dapsone can lead to aplastic anemia. ${ }^{[2,3,5-10]}$ In this study, we report the case of a 50 year old male suffering from leprosy who developed aplastic anemia with dapsone $100 \mathrm{mg} /$ day. Development of aplastic anemia with therapeutic doses warrants the careful \& judicious use of the drug so that this serious medical complication can be avoided.
\end{abstract}

\section{Introduction}

Dapsone (diaminodiphenylsulfone), an antileprotic drug, is a sulfonamide derivative which acts by inhibiting folate synthesis. Dapsone may also be used to prevent \& treat Pnemocystitis pneumonia in AIDS patients. Dapsone is usually well tolerated however; some patients may develop hemolytic anemia particularly if they have G6PD deficiency. ${ }^{[1]}$

In recent times few case reports have reported the occurrence of aplastic anemia with Dapsone; however the data is still sparse. ${ }^{[2]}$ To add to this literature we report a case of a 50 year old male who developed aplastic anemia while on therapeutic doses of Dapsone.

\section{Case Report}

A 50 year old male presented in the skin outpatient department of the district hospital 12 months back with complaints of symmetrical distributed skin nodules, raised plaques/ diffuse dermal infiltration on the face \& symmetrical nerve trunk enlargement. He was initially treated with rifampicin $(600 \mathrm{mg} / \mathrm{d})$, clofazamine $(50$ $\mathrm{mg} /$ day $) \&$ dapsone $(100 \mathrm{mg} / \mathrm{d})$. His present complaints started 5 months after initiating the therapy. There was no history of any substance abuse or the use any other concomitant medicines during this period.

The patient came to the medicine OPD 7 months back with the complaints of fatigue, generalized weakness, breathlessness \& tachycardia. Bone marrow biopsy showed marked hypocellular marrow for age \& peripheral blood examination showed pancytopenia indicating the possibility of acquired aplastic anemia. Following this he was admitted in the male medicine ward \& dapsone $(100 \mathrm{mg} / \mathrm{d})$ was withdrawn from the treatment. The patient was then given two units of blood transfusions \& after which another 5 units have been transfused till now. Currently the patient has been started on rifampicin $(600 \mathrm{mg} / \mathrm{d})$, ofloxicin \& minocyclin.

\section{Discussion}

Aplastic anemia is a rare and often fatal hematological disease. Up to $74 \%$ of cases reported in case series published in the literature are classified as idiopathic. Infections, drugs, solvents and other chemical agents have been associated with aplastic anemia, but it is difficult to prove whether there is a causal relationship, given the absence of confirmatory cases. ${ }^{[3]}$ Dapsone is a drug that is known to be associated with serious hematological ADR, including agranulocytosis, ${ }^{[4]}$ hemolytic anemia and, ${ }^{[6,7]}$ more rarely, aplastic anemia. ${ }^{[8,9]}$ Aplastic anemia seen with dapsone may be either of two types; early or late. Early onset bone marrow toxicity is usually detected during or shortly after drug exposure, may be dose-related, and is usually reversible. Late onset aplastic anemia does not depend on the dose and duration of exposure, and is irreversible..$^{[9,13-15]}$ 
Hematological adverse reactions reported with rifampicin \& clofazamine include hemolytic anemia ${ }^{[10,11]} \&$ leucopenia respectively. ${ }^{[13]}$ Till now there are no case reports of aplastic anemia with rifampicin or clofazamine used alone. ${ }^{[3]}$

In our case aplastic anemia developed 4 months after the initiation of MDT. A non-fatal case of dapsone-induced aplastic anemia was reported in 1985 in a patient with lepromatous leprosy who was taking a daily $50 \mathrm{mg}$ dose for about 24 days. ${ }^{[9]}$ Another case was a patient with bullous systemic lupus erythematosus taking a daily dose of dapsone that ranged from 25 to $200 \mathrm{mg}$ over 4 months ${ }^{[8]}$ Three other cases, all of them fatal, were reported to the Food and Drug Administration (FDA). ${ }^{[9]}$

One might ask whether this case of aplastic anemia could have been prevented if regular blood counts had been performed during the first month of therapy. The fact is that regular blood counts will not prevent the occurrence of the ADR. They will only permit earlier recognition of their occurrence. Moreover given the rarity of aplastic anemia, it is debatable whether regular blood counts in patients under MDT can be recommended on these grounds. However, given that there are other more common MDT-associated hematological ADR, and that blood counts are not particularly complex or costly, it might be sensible to recommend ordering these tests every month perhaps during the first year of treatment so that this rare but fatal complication can be diagnosed early

\section{References}

[1]. Petri WA. Chemotherapy of tuberculosis, mycobacterium avium complex disease, \& leprosy. In: Brunon LL, Lazo JS, Parker KL, editors. Goodman Gilmans the Pharmocological Basis of therapeutics. 11 ${ }^{\text {th }}$ ed.USA: MacGraw- Hill Publications; $2006 . p$ 1203-23.

[2]. Puavilai S, Chutha S, Polnikorn N, Timpatanapong P, Tasanapradit P, Charuwichitratana S etal. Incidence of anemia in leprosy patients treated with dapsone. J Med Assoc Thai; 67 (7): 404-7.

[3]. Goulart IMB, Reis ACS, Rezende TNMD, Borges AS, Ferreira MS, Nishioka SA. Aplastic anemia associated with multi drug therapy (dapsone, rifampicin \& clofazamine) in patient with lepromtous leprosy. Lepr Rev 2005; 76: 167-9.

[4]. Coleman MD. Dapsone-mediated agranulocytosis: risks, possible mechanisms and prevention. Toxicology 2001; 162: 53-60.

[5]. Bhat RM, Radhakrishnan K. A case report of fatal dapsone-induced agranulocytosis in an Indian mid-borderline leprosy patient. Lepr Rev 2003; 74: 167-170.

[6]. Kaluarachchi SI, Fernandopulle BM, Gunawardane BP. Hepatic and haematological adverse reactions associated with the use of multidrug therapy in leprosy - a five year retrospective study. Ind J Lepr 2001; 73: 121-9.

[7]. Lee KB, Nashed TB. Dapsone-induced sulfone syndrome. Ann Pharmacother 2003; 37: 1044-6.

[8]. Woodbury GR Jr, Fried W, Ertle JO, Malkinson FD. Dapsone-associated agranulocytosis and severe anemia in a patient with leucocytoclastic vasculits. J Am Acad Dermatol 1993; 28: 781-3.

[9]. Foucauld J, Uphouse W, Berenberg J. Dapsone and aplastic anemia. Ann Intern Med 1985; 102: 139.

[10]. Martinez E, Collazos J, Mayo J. Hypersensitivity reactions to rifampin: pathogenetic mechanisms, clinical manifestations, management strategies and review of the anaphylactic-like reactions. Medicine Baltimore 1999; 78: 361-9.

[11]. Ahrens N, Genth R, Salama A. Belated diagnosis in three patients with rifampicin-induced immune haemolytic anaemia. Br J Haematol 2002; 117: 441-3.

[12]. Nishioka SA, Goulart IM, Nunes-Araujo FR et al. Severe thrombocytopenia and intermittent use of rifampin. Int J Lepr Other Mycobact Dis 1992; 60: 273-4.

[13]. Karat AB, Jeevaratnam A, Karat S, Rao PS. Double-blind controlled clinical trial of clofazimine in reactive phases of lepromatous leprosy. BMJ 1970; 1: 198-200.

[14]. Graham WR Jr. Adverse effects of dapsone. Int J Dermatol 1975; 14: 494-500.

[15]. Coleman MD. Dapsone: modes of action, toxicity and possible strategies for increasing patient tolerance. Br J Dermatol 1993; 129 : 507-13. 